\title{
Depth estimation of fumarolic gas source deduced by fume pressure measurement
}

\author{
Takehiko Mori ${ }^{1}$, Takashi Suzuki ${ }^{2}$, Jun'ichi Hirabayashi $^{3}$, Kenji Nogami $^{3}$, \\ Michiko Ohwada ${ }^{1}$, and Shin Yoshikawa ${ }^{4}$ \\ ${ }^{1}$ Geological Survey of Japan, National Institute of Advanced Industrial Science and Technology, Tsukuba, Ibaraki, Japan \\ ${ }^{2}$ Tonen General Sekiyu K.K., Sakai, Osaka, Japan \\ ${ }^{3}$ Volcanic Fluid Research Center, Tokyo Institute of Technology, Meguro, Tokyo, Japan \\ ${ }^{4}$ Aso Volcanological Laboratory, Graduate School of Science, Kyoto University, Minamiaso, Kumamoto, Japan
}

(Received February 13, 2008; Revised June 11, 2008; Accepted June 13, 2008; Online published September 8, 2008)

\begin{abstract}
The origin of fumarolic gas is hydrothermal boiling in the active fumarolic area and magma degassing in the active volcano where high temperature gas is discharged. The determination of the fumarolic gas source is important for understanding the geothermal activity or the eruption process. However, it is difficult to determine the gas source by geophysical prospecting using seismic or geomagnetic techniques due to the resolution limitation of these techniques. New measurement tools are therefore necessary. The aim of this study was to determine the conduit length—i.e., the depth of the fumarolic gas source-by measuring the fume pressure, which in turn facilitates the determination of the pressure oscillation of a conduit generated by acoustic resonance. We initially assembled the measuring device and measured the fume pressure at an active fumarole in Kusatsu-Shirane volcano, Japan. Our measuring device succeeded in measuring the pressure oscillation generated by acoustic resonance, revealing that the fumarolic gas source at Kusatsu-Shirane volcano has a depth of approximately $40 \mathrm{~m}$. We propose that the use of an acoustic resonance is an effective approach for deducing the fumarolic gas source.
\end{abstract}

Key words: Fumarolic gas source, acoustic resonance, fume pressure.

\section{Introduction}

Geophysical prospecting using seismology and geomagnetic techniques has been carried out at various active volcanic sites with the aim of obtaining geophysical information, such as location and size of a hydrothermal region or a magma reservoir, relevant for the accurate prediction of volcanic activity (e.g., Tsutsui and Sudo, 2004; Nurhasan $e t$ al., 2005; Onizawa et al., 2005). The results from studies of volcanic tremors occurring at active volcanoes indicate that volcanic fluid or magma is related to the source mechanisms of the volcanic activity (e.g., Tameguri et al., 2007; Mori et al., 2008). Based on such results, it has been suggested that the source mechanisms of harmonic and long period tremors that have a resonant frequency are resonance phenomena occurring in the conduits or cracks filled with volcanic fluid or gas (e.g., Schlindwein et al., 1995; Yamamoto et al., 1999; Maryanto et al., 2008). However, the exact depth from the surface to the layer separating the vapor and liquid phases and to the magma head in a conduit cannot be obtained by geophysical prospecting or associated seismic observations. In order to understand the mechanisms associated with volcanic eruptions, it is very important to know the exact depth because the layer separating the vapor and liquid phases (boiling position) and the magma head (de-

Copyright (c) The Society of Geomagnetism and Earth, Planetary and Space Sciences (SGEPSS); The Seismological Society of Japan; The Volcanological Society of Japan; The Geodetic Society of Japan; The Japanese Society for Planetary Sciences; TERRAPUB gassing position) is responsible for the initial location of a potential eruption or phreatic explosion. The boiling and degassing positions are the locations where the vapor phase and the liquid phase separate. It is currently accepted that in a conduit, acoustic resonance is generated where the vapor phase (volcanic gas) is dominant. We have hypothesized that the depth of the fumarolic gas source can be determined by measuring the acoustic resonance of the conduit. To test this hypothesis, we have measured the pressure oscillation in a conduit generated by acoustic resonance at a vent and determined the length of the conduit filled with fumarolic gas.

\section{Methodology}

Acoustic resonance can be used to measure the length of an underground pipe or a curved pipe (e.g., Latham, 1974; Ichinomiya and Sakamoto, 1991). We believe that acoustic resonance can also be used to measure the conduit length. Volcanic gas (i.e., vapor phase) is dominant in the conduit from the boiling (degassing) position to the surface (Fig. 1(a)). When sound waves are excited in the vapor phase region of the conduit, acoustic resonance is generated. The pressure fluctuation due to this acoustic resonance can be determined by measuring the fume pressure. The installation of an artificial sound source near an active fumarole is not feasible because fumarolic gas has a high velocity and a high temperature. However, continuous fumarolic activity in a fumarole suggests that the vapor and liquid phases are continuously separated-i.e., boiling or 


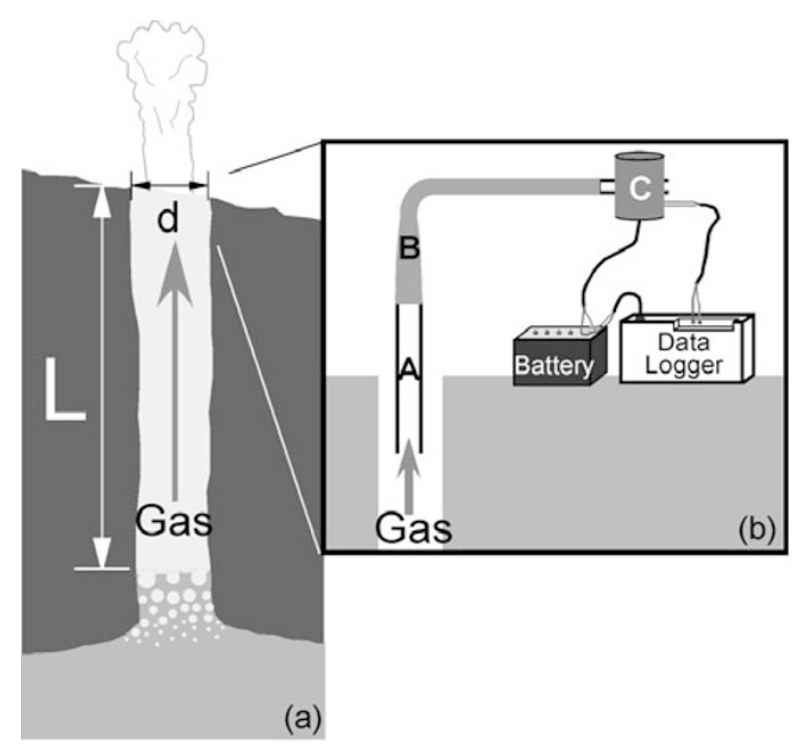

Fig. 1. (a) Schematic illustration of a conduit at an active fumarole. $L$ denotes the conduit length, i.e., the depth of the fumarolic gas source, and $d$ denotes the diameter of the vent. Boiling occurs continuously at depth $L$, and fumarolic gas is continuously discharged from the fumarole. (b) Measuring device assembled to measure the fume pressure. $A$ indicates a quartz glass pipe with a length of $0.5 \mathrm{~m} ; B$, the rubber tubing with a length of $0.7 \mathrm{~m}$; $C$, the differential pressure transducer (MKS; Type 223). The data logger is a LS-8000SH type with a 16-bit data resolution (Hakusan Co.).

magma degassing is in progress - in a deep region; boiling and magma degassing are known to generate sound waves which, in turn, generate acoustic resonance.

A conduit can be assumed to be an open-ended sound tube since it has a fumarole that serves as an opening plane, while the boundary between the vapor and liquid phases serves as a closing plane. If boiling or magma degassing act as a sound source, the conduit length ( $L$; see Fig. 1(a)) can be represented as

$$
L+0.3 d=(2 m-1) \frac{c}{4 f} \quad(m=1,2,3, \cdots),
$$

where $d$ is the diameter; $c$ is the sound velocity; $f$ is the resonance frequency. Although Eq. (1) has an open end correction term, $0.3 d$ (Levine and Schwinger, 1948), the discussion regarding the coefficient of this term can be disregarded because it will be shown that the conduit length is 100-fold larger than the conduit diameter (approximately $0.1 \mathrm{~m}$ ). The sound velocity in the conduit, which is an unknown parameter in Eq. (1), can be represented as

$$
c=\sqrt{\frac{\kappa R T}{M}},
$$

where $\kappa$ is the heat capacity ratio; $R$ is the gas constant; $T$ is the temperature (Kelvin); $M$ is the molar weight. The molar weights and heat capacity ratio are decided based on the component ratio of the observed fumarolic gas. Since the temperature of the fumarolic gas has the largest effect on the sound velocity, we measured the temperature while measuring fume pressure, using special thermometers, such as a platinum resistance thermometer or a chromel-alumel thermocouple. Based on our data on fume pressure, we were able to measure the resonant frequency. Consequently, the conduit length can be obtained from Eqs. (1) and (2).

We assembled a device similar to the one used for estimating the fumarolic gas velocity (e.g., Saito et al., 1988) to measure the pressure oscillation in the fumaroles (Fig. 1(b)). Three differential pressure transducers (MKS223BD) with a full scale range of $133.322 \mathrm{~Pa}$, 1333.22 $\mathrm{Pa}$, and 13332.2 $\mathrm{Pa}$, respectively, and a resolution that is $0.01 \%$ of the full scale were prepared, and the transducer to be used for measuring the fume pressure of the fumarole was selected based on the pressure intensity of the fumarole. In order to measure the pressure oscillation generated by acoustic resonance, we had to reduce the sampling interval of the recorder. A measurement time of more than 10 min was selected in order to be able to distinguish between the pressure oscillation generated by acoustic resonance and that generated by an irregular oscillation. To satisfy all these requirements we selected a data logger (LS$8000 \mathrm{SH})$ that is used for seismic observations. Additionally, if a long time is required for the measurement, it must be ensured that the pipe is not clogged with sulfur sublimated from fumarolic gas. Therefore, we selected a quartz glass pipe with a large diameter for insertion into the fumarole. The total length (from the intake to the differential pressure transducer) of the measuring device was approximately $1.2 \mathrm{~m}$. The quartz glass pipe can measure the stagnation pressure of a vent. The quartz glass pipe was inserted into the fumarole and then attached to it in order to reduce the effects of turbulent flow near the vent and the characteristic noise of the instrument caused by the fumarolic gas.

\section{Observation and Spectral Analysis}

\subsection{Performance test of the measuring device}

A performance test was carried out to confirm whether the pressure oscillation generated by acoustic resonance can be measured with our measuring device. The site chosen for this test was the heat-exchanger plant of the Yunotani spa at Aso volcano, Japan. Here, steam is discharged at approximately $120^{\circ} \mathrm{C}$ from an exhaust pipe that is $0.17 \mathrm{~m}$ in diam-

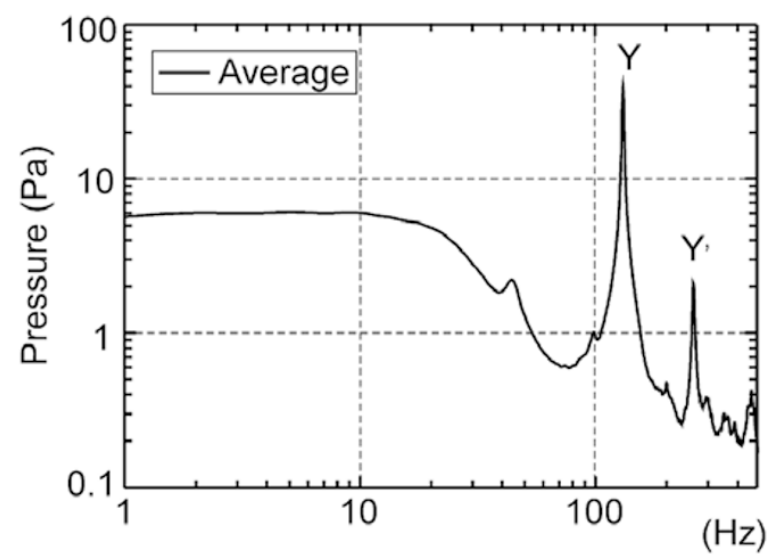

Fig. 2. Average spectrum of 643 spectra obtained at the heat-exchanger plant in Yunotani spa, Japan. The pressure oscillation was sampled at $1000 \mathrm{~Hz}$. The spectrum was calculated at 1-s intervals with 4096 data points (approximately 4 s) using FFT; 643 spectra were obtained. Y and $\mathrm{Y}^{\prime}$ are the fundamental and overtone mode of the resonant frequency, respectively, and are generated by acoustic resonance. 
eter. We measured the oscillation of the fume pressure for 20 min with a sampling frequency of $1000 \mathrm{~Hz}$. Frequency analysis using Fast Fourier Transform (FFT) revealed that the dominant frequency of the measured pressure oscillation was $133 \mathrm{~Hz}(\mathrm{Y})$. It also revealed the presence of a distinct peak at $266 \mathrm{~Hz}\left(\mathrm{Y}^{\prime}\right)$, which is twice the dominant frequency (Y), and of some weak peaks (e.g., 45, 102, 205, and $470 \mathrm{~Hz}$ ) (Fig. 2). We considered the peak frequencies $\mathrm{Y}$ and $\mathrm{Y}^{\prime}$ to be the resonant frequencies generated by the acoustic resonance of an open-ended conduit because $\mathrm{Y}^{\prime}$ is twice Y. In this performance test, the source of acoustic resonance was either the exhaust pipe of the heat-exchanger plant or our measuring device. The measuring device consisted of open-ended sound tube planes: the intake served as the opening plane, while the differential pressure transducer served as the closing plane. The sound velocity of the pipe was equal to the atmospheric sound velocity. From Eq. (1), if the length of the measuring device is $1.2 \mathrm{~m}$, the frequencies of the fundamental and overtone modes of the resonant frequency will be 90 and $268 \mathrm{~Hz}$, respectively $(350 \mathrm{~m} / \mathrm{s}$ at $25^{\circ} \mathrm{C}$ ). If the air temperature inside the pipe rises due to the heated gas, the sound velocity and resonant frequency will also increase. From Eq. (2), the sound velocity in the exhaust pipe was estimated to be approximately $480 \mathrm{~m} / \mathrm{s}$ because approximately $97 \%$ of the steam discharged by the heat-exchanger plant was $\mathrm{H}_{2} \mathrm{O}$ (Yamasaki et al., 1978) and the temperature of the steam was approximately $110^{\circ} \mathrm{C}$ (according to our measurements). Further, the length of the open-ended type sound tube was estimated to be approximately $1.7 \mathrm{~m}$ since the fundamental and overtone modes of the resonant frequencies were measured to be 133 and $266 \mathrm{~Hz}$, respectively. At the heat-exchanger plant, which contains only a few valves, the nearest valve from the exhaust port is at a distance of $1.7 \mathrm{~m}$ from the port. If a valve is not closed and if there is a significant difference between the diameter of the valve and that of the pipe, the acoustic resonance generated will be of an open-ended type. On the basis of these results, we considered the exhaust pipe of the heat-exchanger plant to be the source of the resonant frequency with open-ended type characteristics $Y$ and $\mathrm{Y}^{\prime}$. Low peak frequencies, with the exception of $\mathrm{Y}$ and $\mathrm{Y}^{\prime}$, may be due to the acoustic resonance caused by other valves; however, it is difficult to discuss the origin of the pressure oscillation with these periods because the relation between the fundamental and overtone modes is not clear. The performance test proved that our measuring device can measure pressure oscillation using the acoustic resonance of a pipe. However, it should be noted that the frequency of acoustic resonance produced by the pipe is generated in a frequency band higher than $100 \mathrm{~Hz}$.

\subsection{Observation at Kusatsu-Shirane volcano}

The pressure oscillation of the fumarolic gas was measured in Kusatsu-Shirane Japan, at fumarole N10 (Ohwada et al., 2003), which is the most active fumarole in this area. The measured temperature of the fumarolic gas at N10 was $105^{\circ} \mathrm{C}$ and is almost constant throughout the year. We performed two measurements; in both cases the recording time was 12 min and the sampling frequency was $250 \mathrm{~Hz}$. During the first measurement, the fume pressure (stagnation pressure) increased by approximately $200 \mathrm{~Pa}$ and then decreased within 12 min (Fig. 3(a); 0-742 s). During the second measurement, the fume pressure increased by approximately $200 \mathrm{~Pa}$ - from 300 to $500 \mathrm{~Pa}$-in $12 \mathrm{~min}$, and a fluctuation of approximately $50 \mathrm{~Pa}$ was produced within a period of approximately 2 min (Fig. 3(a); 900-1642 s). These measurement records suggest that the pressure of the fumarolic gas at $\mathrm{N} 10$ has a long cyclic variation, ranging from several hours to several minutes. In the case of oscil-

(a)

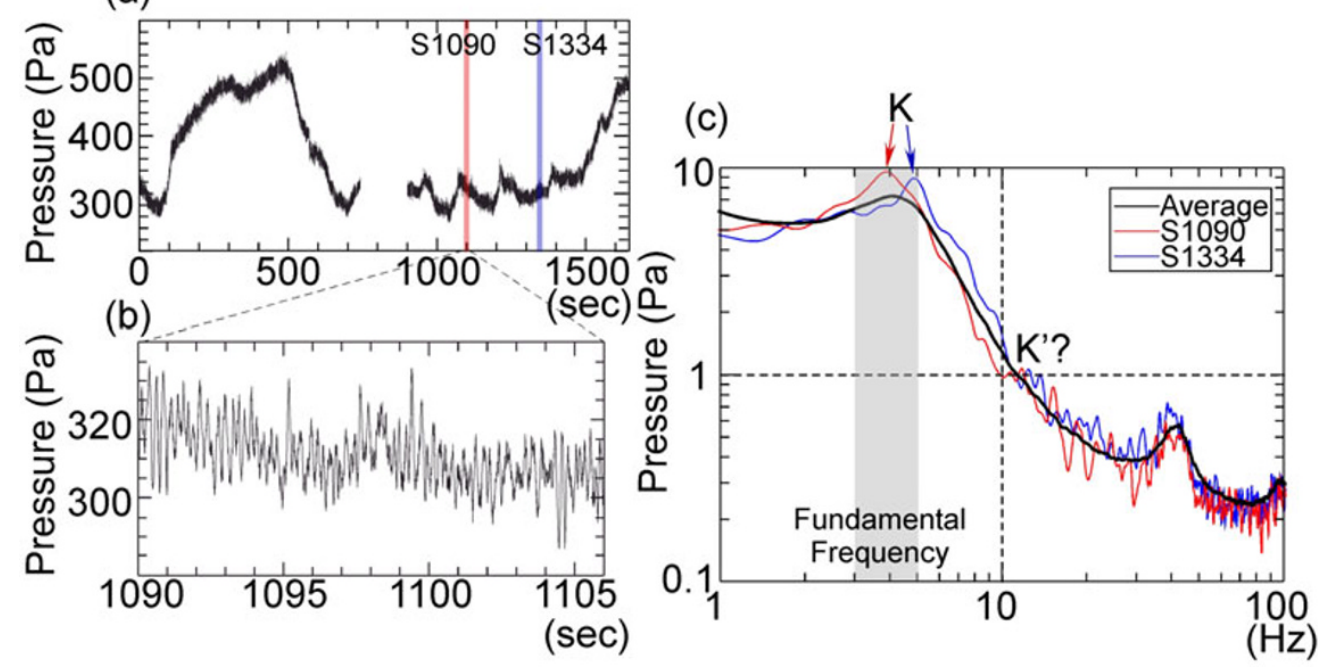

Fig. 3. Waveforms and spectra of pressure oscillation obtained at an active fumarole at the Kusatsu-Shirane volcano, Japan. The pressure oscillation was recorded at a sampling interval of $250 \mathrm{~Hz}$. (a) Waveform of pressure oscillation with a fluctuation of approximately $200 \mathrm{~Pa}$. (b) Increase in the pressure oscillation of the waveform for a period of $16 \mathrm{~s}$ (S1090). The pressure oscillation of fumarolic gas has a period of approximately $0.2 \mathrm{~s}$. (c) Example of the pressure oscillation spectrum. The spectrum was calculated at a time interval of $2 \mathrm{~s}$ with 4096 data points (approximately $16 \mathrm{~s}$ ) using FFT; 726 spectra were obtained. The red and blue lines indicate the S1090 and S1334 spectra, respectively. The black line indicates the average spectrum of 363 spectra. $\mathrm{K}$ and $\mathrm{K}^{\prime}$ are the fundamental and overtone modes of the resonant frequency, respectively, and are generated by acoustic resonance. 


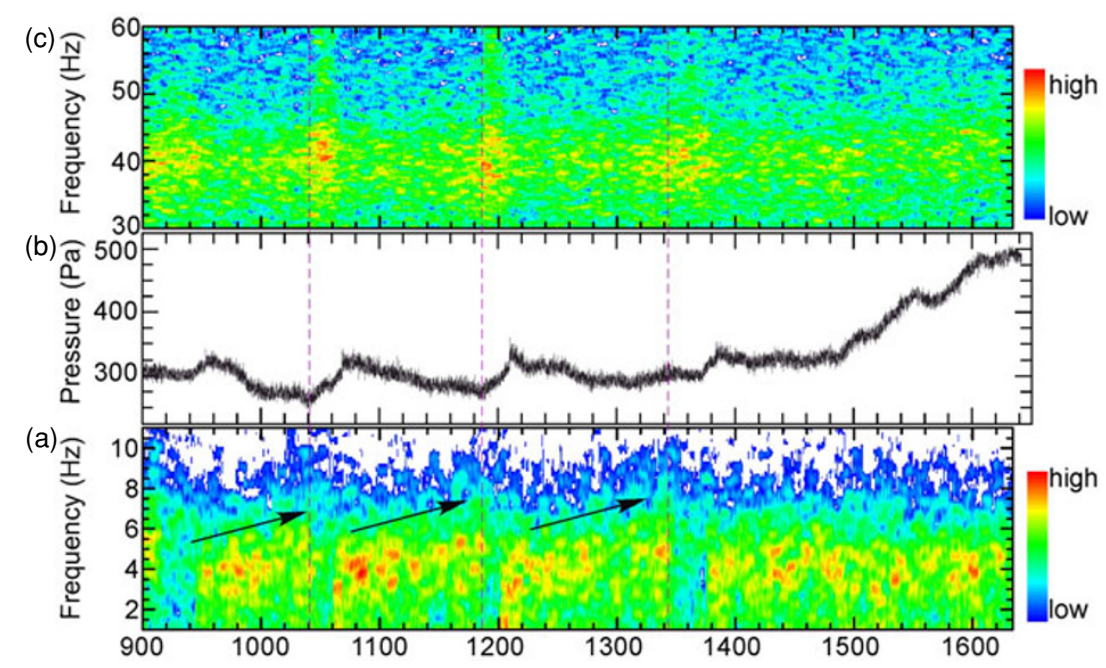

Fig. 4. Waveform and running spectra of pressure oscillation recorded by the second measurement. Two running spectra with frequency bands of 1-11 Hz and 30-60 Hz, respectively, are plotted in (a) and (c), respectively. The intensity of the spectrum was normalized with the maximum amplitude in each frequency band. The spectrum was calculated at a time interval of $2 \mathrm{~s}$ with 4096 data points (approximately $16 \mathrm{~s}$ ) using FFT.

lation with shorter periods, the pressure oscillation of the fumarolic gas had a period of approximately $0.2 \mathrm{~s}$ and an amplitude of approximately $20 \mathrm{~Pa}$ (Fig. 3(b)). This pressure oscillation with a short period was observed during all recording periods (approximately $24 \mathrm{~min}$ ).

The frequency characteristics of the measured pressure oscillations of the fumarolic gas were analyzed using a FFT. A data set with a time window of approximately 16 s (4096 data points) was sampled at intervals of $2 \mathrm{~s}$, and $363 \times 2$ data sets were obtained. In the obtained spectra, the dominant frequencies (K) of the two data sets, S1090 and S1334, were 3.8 and $4.8 \mathrm{~Hz}$, respectively (Fig. 3(c)). The dominant frequency changed from 3 to $5 \mathrm{~Hz}$ during the measurement, becoming $4.0 \mathrm{~Hz}$ on average in 726 spectra. The dominant frequencies indicate the measurement of pressure oscillations of fumarolic gas with short periods, as shown in Fig. 3(b). If the dominant frequencies $(\mathrm{K})$ were to be those of the fundamental mode of the resonant frequency, then the frequencies of the overtone mode $\left(\mathrm{K}^{\prime}\right)$ would be set to approximately $12 \mathrm{~Hz}$. Although the spectral peaks are not distinct when compared with the spectrum of the pressure oscillation obtained at the heat-exchanger plant (Fig. 2), the overtone modes of the spectral peaks appeared at $11.6 \mathrm{~Hz}$ (S1090) and $13.6 \mathrm{~Hz}$ (S1334). At the natural fumarole, since the unstable gas flow was considered to generate a weak resonance oscillation, the overtone mode would naturally become indistinct. It is therefore likely that the dominant frequency $(\mathrm{K})$ is in the fundamental mode of the resonant frequency generated by the acoustic resonance. Moreover, distinct peak frequencies of approximately 40 and $100 \mathrm{~Hz}$ were observed (Fig. 3(c)). The same was not observed by measurements at other active fumaroles performed with the same measurement system although a dominant period near $40 \mathrm{~Hz}$ was also measured in the heatexchanger plant (Fig. 2). Given these results, there is a high possibility that the source of pressure oscillation is not an instrument but a conduit (fumarole). On the other hand, the peak at $100 \mathrm{~Hz}$ may represent the resonant frequency of the device.
The running spectrum was calculated to investigate whether the dominant frequency has a time variation. The fume pressure recorded by the second measurement (from $900 \mathrm{~s}$ ) had many characteristic time variations (Fig. 4). A fluctuation in pressure-which increases by approximately $50 \mathrm{~Pa}$ within a short time (less than $40 \mathrm{~s}$ ) — was recorded four times during the second measurement (Fig. 4(b); 940, 1040, 1190 and $1370 \mathrm{~s}$ ). In the calm stage during each pressure increase, the dominant frequency indicated a slow increase to $5 \mathrm{~Hz}$ from $3 \mathrm{~Hz}$. For example, the dominant frequency was approximately $3 \mathrm{~Hz}$ at around $1070 \mathrm{~s}$, at which time point the fume pressure stopped increasing; the dominant frequency subsequently gradually increased and was greater than $5 \mathrm{~Hz}$ at around $1190 \mathrm{~s}$, at which point the fume pressure started increasing again. Another characteristic observed was related to an increase in fume pressure: when the fume pressure increased, the pressure oscillation with low frequency (Fig. 4(a); approximately $4 \mathrm{~Hz}$ ) became weak and the pressure oscillation with high frequency (Fig. 4(c); approximately $40 \mathrm{~Hz}$ ) became strong (e.g., 1040-1070, 1190-1210 s).

\section{Discussion}

The pressure oscillation of the fumarolic gas with a dominant frequency of approximately $4 \mathrm{~Hz}$, which was considered to be the resonant frequency, was measured at the N10 fumarole of the Kusatsu-Shirane volcano. From Eq. (2), the sound velocity in the conduit was estimated to be approximately $480 \mathrm{~m} / \mathrm{s}$ because the fumarolic gas primarily contained $\mathrm{H}_{2} \mathrm{O}(98 \%)$ and its temperature was determined to be $105^{\circ} \mathrm{C}$. This sound velocity assumes the density of saturated water vapor. Since the density of fumarolic gas increases with an increase in its water content, the sound velocity that is proportional to the negative one-half power of density becomes slow. However, the fumarolic gas inside the conduit can be considered to be almost dry because the temperature of the fumarolic gas at N10 is above the boiling point at that altitude. Although it is difficult to estimate the density of the fumarolic gas inside the conduit, it 
can be assumed that the error pertaining to sound velocity is not significant (less than $30 \%$ ) because the fumarolic gas at N10 exceeding the boiling point at that altitude is almost dry.

When the resonant frequency was $4 \mathrm{~Hz}$, the conduit length $(L$; Fig. 1(a)) for a vent diameter of $0.2 \mathrm{~m}$ was calculated to be approximately $30 \mathrm{~m}$ using Eq. (1). Hashimoto et al. (2004) performed a resistivity survey in the fumarolic area on the north-side of Kusatsu-Shirane volcano; their survey clearly revealed the existence of low-resistivity hydrothermal layers at a depth of more than $50 \mathrm{~m}$. These hydrothermal layers are approximately $20 \mathrm{~m}$ deeper than the conduit (boiling position) estimated by us. Since the depth at which liquid boils is less than $40 \mathrm{~m}$, even if the sound velocity error is taken into consideration, as shown in Fig. 1(a), the boiling occurs at the position where the liquid is shot up by several tens of meters from the hydrothermal layer inside a conduit. The length $(L)$ of the conduit varied from 24 to $40 \mathrm{~m}$ because the dominant frequency changed from 3 to $5 \mathrm{~Hz}$ during the measurements. The fluctuation in the dominant frequency (i.e., the fluctuation of the boiling position) was not random; rather it was synchronized with the pressure fluctuation, which could be converted into a fluctuation of the fumarolic-gas flux. In order to clarify what the synchronization of these two oscillations indicates, we need to observe the time variation of the conduit length at some future measurement by continuously measuring the temperature and density of the fumarolic gas.

\section{Conclusion}

We attempted to determine the conduit length-i.e., the depth of the fumarolic gas source-by measuring the fume pressure and the pressure oscillations at an active fumarole of the Kusatsu-Shirane volcano. A performance test for the measurement device assembled by us was carried out at a heat-exchanger plant. During the performance test, the measuring device proved itself capable of measuring the pressure oscillation generated by acoustic resonance. However, there is a possibility that the acoustic resonance of a measurement device itself generates a high-frequency pressure oscillation (e.g., over $90 \mathrm{~Hz}$ ). We recorded the pressure oscillation of the fumarolic gas at Kusatsu-Shirane volcano and observed fluctuations in the oscillation with different periods (hours, minutes, and less than $1 \mathrm{~s}$ ). The spectrum analysis of the measured pressure oscillation revealed the existence of peak frequencies of approximately 4, 40, and $100 \mathrm{~Hz}$. The pressure oscillation with a dominant frequency of approximately $4 \mathrm{~Hz}$ was a dominant periodic oscillation with a constant amplitude of $20 \mathrm{~Pa}$; there also existed a weak spectrum peak at approximately $12 \mathrm{~Hz}$, which is equivalent to the overtone mode with a frequency of approximately $4 \mathrm{~Hz}$. Based these results, we estimated that the pressure oscillation with a period of approximately $4 \mathrm{~Hz}$ was generated by the acoustic resonance of the conduit with a length of approximately $30 \mathrm{~m}$. However, it was difficult to determine the sources of the peak frequencies of 40 and $100 \mathrm{~Hz}$ because there was a possibility that the resonance of the measuring device produced a high-frequency oscillation. Consequently, although we were able to prove it possible to determine the conduit length (i.e., depth of the fu- marolic gas source) by fume pressure measurement, it will be necessary to improve the measurement method for cases where the source of fumarolic gas is at a shallow depth (i.e., for cases in which resonance occurs with a high frequency).

Acknowledgments. We thank Dr. Y. Sudo and Dr. M. Yoshikawa of the Aso Museum and the staff members of the Volcanic Fluid Research Center, Tokyo Institute of Technology for providing assistance in our observation. We are also grateful to Dr. H. Shinohara of the AIST for helpful comments. We would like to thank Dr. T. Nishimura and anonymous reviewer for their constructive comments.

\section{References}

Hashimoto, T., T. Mogi, Y. Nishida, Y. Ogawa, J. Hirabayashi, M. Oikawa, M. Saito, S. Mizuhashi, N. Ujihira, Nurhasan, and T. Wakabayashi, High-density electrical sounding and self-potential profiling at KusatsuShirane volcano, 4th Joint Observation of Kusatsu-Shirane Volcano (July-November 2003), 133-142, 2004 (in Japanese).

Ichinomiya, R. and S. Sakamoto, A new method of measuring length of pipe by means of sound signals (Detecting resonant frequency of air column in pipe), JSME Int. J., 57, 2217-2223, 1991 (in Japanese with English abstract).

Latham, F. G., An acoustic resonance technique for finding breaks in GasFilled pipes, Appl. Acoustics, 8, 119-132, 1975.

Levine, H. and J. Schwinger, On the radiation of sound from an unflanged circular pipe, Phys. Rev., 73, 383-406, 1948.

Maryanto, S., M. Iguchi, and T. Tameguri, Constraints on the source mechanism of harmonic tremors based on seismological, ground deformation, and visual observations, J. Volcanol. Geotherm. Res., doi:10.1016/j.jvolgeores.2007.10.004, 2008 (in press).

Mori, T., Y. Sudo, T. Tsutsui, and S. Yoshikawa, Characteristics of isolated hybrid tremor (HBT) during a calm activity period at Aso Volcano, Bull. Volcanol., doi:10.1007/s00445-007-0185-7, 2008 (in press).

Nurhasan, Y. Ogawa, N. Ujihara, S. B. Tank, Y. Honkura, S. Onizawa, T. Mori, and M. Makino, Two electrical conductors beneath KusatsuShirane volcano, Japan, imaged by audiomagnetotellurics, and their implications for the hydrothermal system, Earth Planets Space, 58, 1053-1059, 2005.

Ohwada, M., T. Ohba, J. Hirabayashi, K. Nogami, K. Nakamura, and K. Nagao, Interaction between magmatic fluid and meteoric water, inferred from ${ }^{18} \mathrm{O} /{ }^{16} \mathrm{O}$ and ${ }^{36} \mathrm{Ar} / \mathrm{H}_{2} \mathrm{O}$ ratios of fumarolic gases at the Kusatsu Shirane volcano, Japan, Earth Planets Space, 55, 105-110, 2003.

Onizawa, S., T. Mori, T. Tsutsui, J. Hirabayashi, K. Nogami, Y. Ogawa, T. Matsishima, and A. Suzuki, Shallow P-wave velocity structure of Shirane pyroclastic cone, Kusatsu-Shirane volcano derived from a controlled seismic experiment, Bull. Volcanol. Soc. Jpn., 50, 9-16, 2005 (in Japanese with English abstract).

Saito, G., H. Shinohara, and S. Matsuo, Effect of flow velocity on temperature and chemical composition of fumarolic gases at Mt. Usu, Hokkaido, Japan, Rendiconti della Societá Italiana di Mineralogia e Petrologia, 43, 1253-1263, 1988.

Schlindwein, V., J. Wassermann, and F. Scherbaum, Spectral analysis of harmonic tremor signals at Mt. Semeru volcano, Indonesia, Geophys. Res. Lett., 22(13), 1685-1688, 1995.

Tameguri, T., S. Maryanto, and M. Iguchi, Source Mechanisms of Harmonic Tremors at Sakurajima Volcano, Bull. Volcanol. Soc. Jpn., 52, 273-279, 2007.

Tsutsui, T. and Y. Sudo, Seismic reflectors beneath the central cones of Aso Volcano, Kyushu, Japan, J. Volcanol. Geotherm. Res., 131, 33-58, 2004.

Yamamoto, M., H. Kawakatsu, S. Kaneshima, T. Mori, T. Tsutsui, Y. Sudo, and Y. Morita, Detection of a crack-like conduit beneath the active crater at Aso volcano, Japan, Geophys. Res. Lett., 26(24), 3677-3680, 1999.

Yamasaki, T., M. Hayashi, A. Koga, T. Noda, and M. Fukuda, Steam wells at the Yunotani geothermal field in Aso caldera and its exploration, $J$. Geotherm. Res. Soc. Jpn., 15, 19-30, 1978 (in Japanese with English abstract).

T. Mori (e-mail: mori.may0212@aist.go.jp), T. Suzuki, J. Hirabayashi, K. Nogami, M. Ohwada, and S. Yoshikawa 